\title{
When Corporal Acts Are Labeled Criminal: Lack of Privacy among the Homeless
}

\author{
Matthew R. Taylor*, Eileen T. Walsh \\ Department of Sociology, California State University, Fullerton, CA, USA \\ Email: ^taylor005@gmail.com
}

How to cite this paper: Taylor, M. R., \& Walsh, E. T. (2018). When Corporal Acts Are Labeled Criminal: Lack of Privacy among the Homeless. Sociology Mind, 8, 130-142.

https://doi.org/10.4236/sm.2018.82011

Received: February 14, 2018

Accepted: March 31, 2018

Published: April 3, 2018

Copyright ( $\odot 2018$ by authors and Scientific Research Publishing Inc. This work is licensed under the Creative Commons Attribution International License (CC BY 4.0).

http://creativecommons.org/licenses/by/4.0/

(c) (i) Open Access

\begin{abstract}
This paper concerns homelessness and its strained relation to personal privacy. The homeless, by and large, have no access to truly private spaces they can lay legitimate claim to-places where they will not be potentially harassed or seen by the public or the police. In this paper, I illustrate some of the experiences the homeless have had while lacking privacy, the ways they adjust to and cope with the loss of privacy, and their attempts to find privacy, however temporarily. In addition, the relations between legality and homeless living are explored alongside some discussion of the homeless shelter system and how people that have stayed in shelters often view it. The methodology implemented in the study involved face-to-face contact and the use of a semi-structured instrument of interview questions concerning the lived experiences encountered by homeless individuals living on the streets in Anaheim and Fullerton in southern California. The direct evidence from the study suggests that many homeless individuals have their reasons for disliking homeless shelters, that their public experiences are inevitably trying and uncomfortable, and that public and police surveillance of their daily activities pose a sort of omnipresent threat to their privacy, possessions and even their bodies. And this threat is of a kind that they have minimal, if any, means to circumvent. I conclude with an examination of the kind of policy-Housing First-that is the best social tool we collectively have, so far, for reducing the number of actively homeless persons.
\end{abstract}

\section{Keywords}

Homeless, Privacy, Corporal as Criminal

\section{Introduction}

As a young, white male I entered the field by frequenting a public park where homeless people routinely congregate; my purpose was to collect data for a mas- 
ter's thesis concerning the lived experiences of homeless people. Conducting in-depth interviews and observations over a period of two years under the supervision of my faculty supervisor, I interviewed twenty homeless people. While my findings do not contradict insights on other ethnographic studies of homeless people, this paper amplifies one aspect of homelessness that has been under-reported-the lack of privacy, which in turn makes mundane bodily functions subject to criminalization. Three themes concerning homelessness and its frayed relationship to privacy appeared from an analysis of the collected data: aversion to public shelters, exposure to the public gaze, and surveillance. This focus on lack of privacy has policy implications and gives insight into the shortcomings of shelters as a solution for the chronically homeless.

\section{Review of Literature}

The related literature for this project demonstrates some of the ways people cope and make do when the circumstances of their lives on the street are strained, extremely trying, and their hardships are seemingly endless. "Chronic homelessness" is defined as a year or longer of continuous homelessness, or repeated bouts of homelessness while struggling with a serious medical condition, mental illness, or substance use disorder (National Alliance to End Homelessness, 2016).

Duneier (1999) presents ethnographic work on homelessness that illuminates how racial inequality results in a disproportionate number of people of color on the street. Further, Duneier shows how a lifetime of systematic, negative bias influences who is at risk of homelessness. In another ethnography, based in San Francisco, Teresa Gowan (2010) reveals the connection between generational lack of opportunity and homelessness among people who chiefly generate money through recycling a variety of materials.

While Duneier captures the experiences of the culturally rich homeless in Greenwich Village, Gowan focuses on the rapidly-changing cityscape of San Francisco. In the meantime, the homeless in southern Californian exurbs-all, in this particular case, located south of Los Angeles-are understudied. So too, are there few ethnographic studies where the poor or destitute person's own perspective is central.

By examination of homeless people's personal histories and lived experiences, we provide understanding not only about the social trajectories that lead to homelessness, but gain insights into the trials of everyday life on the streets and the impediments to recovery.

Padgett and her research colleagues' (2015) work demonstrates that although there is disagreement between researchers and governments concerning the homeless, we have seen a paradigmatic shift in approach thanks to the success of Housing First policies whereby-as the name implies-the homeless are first and foremost provided housing. This approach has been confirmed by studies (Gulcur et al., 2003; Leff et al., 2009) that consistently report findings in support 
of Housing First's cost efficiency. Further, the studies present Housing First's overall success in reducing the number of hospitalizations, the rate of self-destructive behavior like drug abuse, and patients' non-compliance with psychiatric care. Jencks' (1995) demonstrates how the role of crack cocaine, increased divorce rates, deinstitutionalization of the severely mentally ill, and the rising cost of rent correlate with the descent into homelessness.

There are few other studies focusing on the point of view of the homeless. By looking into the themes that emerge from the homeless' personal histories and lived experiences, an improved understanding can be obtained concerning the life paths that are at risk of homelessness, the trials that accompany the experience of it, and the difficulties of escaping unhoused poverty.

\section{Methods}

A burgeoning literature makes compelling arguments that social phenomena must be interpreted through understanding the ways that meaning emerges from interactions and memories (Gubrium \& Holstein, 2002). This theoretical lens informed the in-depth interviews and ethnographic observations that comprise the basis of this research.

As a researcher interested in how unhoused Americans survive on the street I entered the field by frequenting a public park where homeless people routinely congregate. My purpose was to collect data for a master's thesis concerning the lived experiences of homeless people. Over the course of two years and many hours of occupying space in this park, I became a sort of social fixture who engaged in many casual conversations, and gave away cigarettes and snacks until a sufficient enough rapport developed to approach individuals and conduct in-depth interviews with them. Through discussions with my supervising faculty, we examined the themes that emerged from the data we gathered. While a number of these themes, such as food scarcity, are central findings of the overall research project, this paper focuses solely on the issue of privacy and how the lack of privacy poses a central dilemma to the homeless experience, and can result in costly ingress to the criminal justice system - at considerable cost to society and the homeless individuals themselves.

In this sample, we found that people who have been "rough sleeping" on and off for twenty or more years are not uncommon. In fact, around ten years was rather common, with three, more-or-less unbroken, consecutive years of homelessness being the case in around a third of the people interviewed. This paper is based on a study I conducted to look at the experiences, feelings, and personal histories that come with the extreme poverty of homelessness. In addition, this paper aims to add to the literature a better understanding of how people experiencing this condition adjust to, and conceptualize, the circumstances of their homelessness as it relates to privacy.

In the study, homelessness is operationalized by the definition provided by the U.S. Department of Health and Human Services and the National Health Care 
for the Homeless Council, that together define a homeless person as an individual who has no permanent housing, but might stay in an unstable setting such as a single-room occupancy, a homeless shelter, an automobile, an abandoned building, a transitional housing situation, a mission, or are "doubled up" with a friend, acquaintance, or extended family (National Health Care for the Homeless Council, 2017). Almost all of the participants of the study defined as homeless fell into an easily recognizable form of homelessness, having access to no walled-in place whatsoever, be it a car, motel, or a friend's home.

To maximize my success with potential participants, I first looked for disqualifying signals, such as likely indicators of severe mental illness, or overt disturbed behavior like shouting or talking to oneself. If these signs were absent, I approached the group or individual, told them what I was doing, and then just "hung out" for a while, unhurried to proceed with an interview. Next, I mentioned a small, self-funded monetary reward for participating in the interview, making sure to explain that the potential interviewee would be under no obligation to answer any question that they did not want to, and would not have to complete the interview to collect the reward. This approach, combined with a little laughter and naturalness in the company of the homeless, went a long way. I also found that revisiting locations where homeless people can be found built trust with that population, and would sometimes result in previous participants recommending the interview to their friends and peers.

I interviewed a total of twenty (20) adults living without shelter in southern California. Respondents were recruited through convenience sampling, with a purposive technique to capture interviews with the park regulars. The final sample is comprised of four (4) women and sixteen (16) men. The interviews lasted approximately one and a half hours each.

Although we recognize that these homeless individuals are not representative of all homeless, the interview data tap into a wide range of narratives about sleeping rough. Therefore, at the risk of over simplification, it is necessary to make some generalizations. To avoid making erroneous generalizations, each of the respondents' quotes is put into context within a summary of what they reported during the in-depth interview. We include a brief description of each respondent presented in this paper in order to allow the reader to access each interviewee's presentation of self.

\section{Findings}

There are three themes about privacy that emerged from the data: aversion to public shelters, exposure to the public gaze, and surveillance. Along with food and water, shelter is a basic human necessity. It is one that, by definition, the homeless lack. While shelter is a need that is less urgent than food and water, it is nonetheless valuable. As we will see in the following pages, an individual's lack of access to private shelter not only promotes dysfunction, but makes the very nature of mundane bodily functions (bathing, sleeping, elimination, affection) 
criminal for possibility of being seen by others.

\section{Aversion to Public Shelters}

Although a seasonal homeless shelter, open from October to March, serves the region, many homeless remain on the street night after night. Not only is this due to limited capacity, but according to the participants in this study there is a strong personal dislike for homeless shelters and the privacy-starved environments they create. The answers the homeless gave for their disinclination to line up at a shelter were relatively simple. Travis, a graying, smiling man at the far end of middle age, said that he preferred to keep to his own company. Quiet and taciturn, a recovering alcoholic with more than two decades of sobriety, Travis, sitting down on a curb behind his stuffed shopping cart, said of the shelter:

"They give you about this much space" (as he gestured with about three inches between his thumb and index finger). "It's too tight in there. People snore." Travis

Conrad, another homeless man who achieved a long period of sobriety reportedly without any program or professional help, had a long salt-and-pepper goatee and a kind demeanor, but a burning intensity in his eyes. He quipped:

"Shelters are places where people steal from one another, and (my) stuff is safer on (me), or in the storage space I share with my partner" (as he gestured at Pam). Conrad

Pam was a middle-aged woman with dark hair and lips delicately lined with red lipstick. Pam and Conrad told me that over time they'd accumulated a number of things; they even had a laptop computer in the storage space they rented. Conrad told me that after twenty-plus years on the street, he had thoroughly learned the ropes of homelessness, and saw himself, accurately, as one who has not fared as badly as others that had lived a similar number of years on the street. Pam had a stronger opinion than Conrad about homeless shelters. She recounted some unpleasant memories on the topic, saying that in her experience, shelters were unsuitable. She worried about her health at shelters for fear there were people present there infected with tuberculosis and other diseases. She reported that sometimes the men at the public shelters exposed themselves to the women. Further, she said some of the male staff at some shelters "hit on" newly homeless female residents, who tended to be younger, and especially vulnerable due to the confusing nature of their current circumstances.

In such tight, privacy-starved environments it only takes one or two people engaging in these types of behavior to make plenty of people uncomfortable. At the same time, Pam, like all the females interviewed, was very concerned for her safety, especially at night, without so much as a tent to shield her from the public eye and the cold. Pam gravely told me she worried about getting raped or murdered every night she went to sleep. "It's hard to find a place just to lay your head." Conrad, as Pam nodded her head in agreement.

Another frequent complaint about shelters was that they ask "too much information of you." Teddy, a man in his 30 s who had been violently attacked in prison and has ever since walked with a cane, said he would perhaps go to the 
Armory or another shelter, but that the environment inside is unpleasant, and too noisy at night to get any sleep. The complaints were varied. When I asked Javier about his experience with shelters he said: "Man, they kick you out before it's even daylight in the morning. So, what's the point?" Javier

So, the sense was that homeless shelters not only were uncomfortable, but that they also offered no privacy or sense of control.

\section{Exposure to the Public Gaze}

The public experience of the homeless is a complicated blend of being ignored, feared, and avoided on the one hand, and receiving occasional kindnesses on the other. While all participants dealt with the constant presentation of self in the public domain, not all of them suffered equally. The women, in particular, reported the most difficulty with loss of privacy. Most said that the public was not too cruel, but there were some notable exceptions. Sleep time was a part of the day when many felt particularly vulnerable. Indeed, Corey, a spunky teenage adult with light skin and a thick head of blonde hair, described being "come up on" by an unknown assailant while he slept. The attacker tried to get away with the participant's backpack - that he was at the time using as a pillow. The attacker didn't get away with the backpack, but only because Corey put up enough of a fight. Not all experiences with the public, however, were so dramatic.

When I asked the participants about what they did when it rained, homeless shelters still did not pass their cost/benefit analysis. Despite the physical risks to health during inclement weather, the majority of the homeless participants chose to remain on the street. Claude, a young sunburned man with a dark beard and a lanky frame, put it this way: "It isn't too big a deal when it rains; you just have to move shit around." Claude

Hera and her husband, Javier, along with Polly, the disenfranchised nurse, and Jerry, another long-term alcoholic, claimed not to worry about rain. The park folks reported that, with the exception of the 7-Eleven, the shops in the strip mall just across the street allowed them to shelter under the overhang when the weather became rainy.

Due to cold, discomfort, and exhaustion, the homeless in my study often did not sleep well at night. A few reported they had almost fully adjusted to "sleeping rough," but the majority reported they didn't sleep well even after years of sleeping rough. Claude, for instance, only slept a few hours a night. Polly said she had not slept well since becoming homeless 7 or 8 weeks prior to our interview. Jerry, an emaciated drinker and former road worker, also slept poorly, but he wasn't apt to complain, having long ago adjusted to the way of the street.

Further, they all noted that there was no place they could go where they were sure to be free from harassment. As one of the homeless men put it: "The police will chase you away from any place." Len

And the public is sometimes unfriendly. Homelessness also provides no recourse from the elements. Heat comes with the day, cold with the night. And the elements are always there. Also, there is no way to wash up without a shower 
truck appearing - and they rarely come around. Laundering and ironing clothing are also almost always out of the question. The homeless also have no private place to store their personal belongings. Hence, the common sight of a homeless person with a shopping cart: the cart functions as closet, hamper, shelf, vault and wardrobe all at once. Often the entirety of their material life is in the cart. And if they are to briefly leave the cart behind for any reason, it must be in somebody's care or the person risks losing all their earthly possessions. Larry, for instance, was almost always physically in contact with his cart. When he closed his eyes to rest whilst sitting on a curb, he always left one hand firmly gripping the side of the cart. Finally, with no claim to private space, the homeless person cannot invite another into one's private space to reinforce friendships or positive connections. The homeless person, in this way, has a unique relation to privacy. Public places, by default, are the only places they can exist in, and yet the people in these public places want little to do with them. They are stuck interminably in a confusing environment that neither welcomes nor integrates them.

Part of the public experience of the homeless involves attempts to generate a little money. One of these methods is panhandling, a behavior that includes begging for spare change or "flying a sign." All of this is done in public places where the unending exposure to the public is used as an asset. Sometimes a person's bad habits are flipped on their head. For instance, Jerry flew a sign that read WHY LIE? NEED BEER. This was an attempt to use his homelessness and his alcoholism to his advantage by combining it with ironic humor. This kind of attempt at using one's lack of privacy as an asset was not uncommon among the homeless I interviewed. Nor was it as easy as it may look; on panhandling:

"It takes work." Polly. "Time for the panhandle scandal." Javier's friend, Miguel.

\section{Surveillance}

Typically, when people are going to be staying out-of-doors for a stretch of time the use of tents is the go-to method of sheltering in the absence of something better. Hera, a stout woman with long dark hair and a friendly and positive attitude, told me that some time ago a church group gave tents to everybody at the park who wanted one. When the tents, representing a modest semblance of privacy, were put to use, however, the surveillance of city workers and police officers resulted in intervention and seizure of the tents. The police and city workers labeled the tents an eyesore and public nuisance. Everybody I talked to who had used a tent said that they provided considerable warmth and comfort compared to an open-air sleeping bag on top of cardboard, but that they draw negative attention. As a result, some of the homeless are cagey talking about just where they sleep. An exchange I had with a young man in his 20 s with scruffy hair, skin marked by acne scars, and surrounded by his luggage, went like this: "So what are you guys doing recently about the rain? And the cold?" Interviewer

"Honestly, we have a tent so if we can't find a roof over our head, we'll make one." Jakob 
"Don't the cops bug you if you set up?" Interviewer

"Yeah, anywhere around here (the downtown near the park), but I mean, if you know the spots, you're good." Jakob

Again and again, the concept of "finding a spot" came up among the participants. A good "spot" is found wherever one can establish, however briefly, even the slightest modicum of privacy. The "spots" people find differ depending on place and time. Sometimes a person seeks out a spot to take a break from their companions, or because of an illness, or a bad mood, or the simple need for some alone time. Some people will go to great lengths to find a good spot to be alone. At one point during the 1990s in Manhattan, for instance, the Metropoli$\tan$ Transit Authority (MTA) hired outreach workers to investigate the subterranean tunnels that slice beneath Manhattan like an underground latticework. The MTA estimated that thousands of human beings lived amid the hidden channels under Manhattan (Jencks, 1995). In contemporary American society, privacy is a sort of cornerstone of our interpersonal conduct. Most Americans can appreciate the value of privacy in promoting comfort, personal growth, intimacy, and the general advancement of one's personal and even professional life. Further, most Americans can access spaces of privacy that reflect their own lives in terms that are both personal and secure. For instance, a housed person can be securely solitary among his or her hobbies, books, thoughts, etc. The private space promotes well-being. For the homeless, this privilege is more than elusive. To meet this basic aspect of American life the homeless are required to improvise. For Jerry, personal space and privacy is partially achieved by ducking into the "Port-O-John" (his name for the plastic outhouses you see at parks and construction sites). Javier attempts to meet his need for privacy by "finding a spot"- that is, isolating from the others. Also, like Jerry, Javier gets his privacy by entering one of the "Port-O-Johns." Javier was a tough-looking, masculine man, arms loaded with tattoos. It seemed he didn't want to admit to having too much of a bad time. I asked if he had all the privacy he wanted. "Somewhat. You do what you can, you know?" Javier

In these situations, the access to private spaces was so utterly unavailable that human beings came to accept a few square feet within a Port-O-John as a suitable replacement for actual privacy. Claude had similar experiences with obtaining privacy on the streets. When I asked him if privacy was hard to find he replied: "Not really. No, public bathrooms and things like that provide you with privacy. The only thing that's hard is like if you have to go to the bathroom and it's late at night and everything is closed. That sucks." Claude

"Do you have all the privacy you want?" Interviewer "Yeah, sure. Yeah. (In a why-not tone of voice). There's a certain hour of the day where there's no one else around." Claude

And so Claude managed a modicum of privacy, but only during "a certain hour of the day." And some of the others managed their modicum of privacy inside Port-O-Johns or bathroom stalls. In considering the words of many of the participants in this study, privacy was better on the streets than in the shelters, 
but the streets too were hardly a haven for privacy. The streets were, in this sense, the lesser of two evils.

However, both on the streets and in the homeless shelters, the homeless person is without a place to store personal items that can be easily and freely accessed on a long-term basis. They have no place to quietly and privately reflect on their own life interests and pursuits, as wherever they position themselves they are exposed to potential surveillance. They have limited access to proper sleep, since for many it is only warm enough to sleep during the day. The homeless person is necessarily limited in diet to whatever is offered via charity and whatever cheap food they can afford, since there is no private place for them to store food and no way for them to freeze, cook or refrigerate their meals. Their circumstances are restrained so that they cannot invite anybody to a place the invitee does not already have access to.

There is an exception to lack of privacy, although it is one rarely accessed by the homeless: a motel room. Motels in the region are not inexpensive, however, and most of the homeless who stay in motels spend less than a week per year sleeping in one. But the privacy that a motel can afford its tenants can be quite valuable. Javier pointed out to me that in the past there was a church or charity service that provided motel vouchers to poor people who needed them. He reflected on how helpful they were for poor people in need, and concluded by saying somewhat ruefully that they now only provided the needy with food-no more vouchers. Cecil, a friendly, grey-haired, dark-skinned man with a long history of drinking, told me that when he gets up enough money for a motel room, he can take a shower, rest, and relax, and that he doesn't need to drink when he's lodging. Even if this is an exaggeration and, when in a motel he drinks less or feels a reduced need to consume alcohol, the sentiment was clear: life feels much better with a bed, a roof, four walls and a true semblance of privacy. Cecil also explained to me that he lost his job as a truck driver when he had his first and only seizure-in front of his co-workers. Homeless young adult Walter told me that he was so desperate for some space of his own he traded a SNAP card with a year's worth of food stamps on it in exchange for one week in a motor lodge. Women reported a greater struggle with privacy than the men. Pam and Polly both attested to having virtually no privacy whatsoever. And they hated the experience. The risks of constant bodily exposure to the elements and the public, combined with extremely infrequent moments of privacy created a unique blend of dissatisfaction. With no recourse to privacy, intimacy also suffered. Javier and Hera, the only married couple I interviewed, described their marriage's lack of privacy in an offhand way, saying it was difficult to keep the marriage together, and that the experience is "different than having a place." Javier spoke of the general idea of romantic intimacy on the street as a "wham-bam-thank-you-ma'am" situation. "In the bushes," he laughed. Javier The idea here was to avoid the prying eyes of the public and, more importantly, the police, who, as Len reports, will "chase you away from any place." And, according to Len and others, the police are vague about where to go to avoid being "chased away" again. 
Jerry's experience with the surveillance of police was extensive. He reported that he'd amassed at least 15 recent police citations and he claimed to have been jailed in four different American states. Like Claude, he felt the police in jail were the most unkind and intimidating of all. Unlike Claude, who expressed some forgiveness toward the manner of the street cops, however, were Jerry's views on those particular policemen. The police helped by providing info on homeless resources, but they hurt, according to Jerry, by "bugging people for small things," and doing so persistently. For example, though Jerry consumed more beer than anything else (he barely ate anything most days, according to him and his companions) the police routinely arrived at the park just to "dump people's beers" and seize their tents or other private belongings. Overall, Jerry said he has been fined more often than he can keep track of. He tried to see some humor in it. He said with a gapped grin, chuckling: "Man, I was once fined $\$ 1500$ for having a shopping cart." Jerry

\section{Discussion}

Among this sample of homeless people, most completely rejected homeless shelters as a viable choice. One reason was a lack of options. There is only one seasonal shelter in the Fullerton and one year-round shelter in the neighboring city of Anaheim that only opened its doors in the year 2017. At the time of the research conducted for this paper, the newer shelter was not yet available for public use. Therefore, some people do not go to homeless shelters simply because they can't get a cot due to lack of space. Another reason is that the conditions in the shelters are cramped. That minimal amount of space clearly made several of the interviewees uncomfortable. If the shelters provided more space, some would be likely to use them. Pam had her own reasons for avoiding homeless shelters. She described them as havens for tuberculosis and inappropriate behavior-sometimes on the part of shelter staff. All this means that people who might otherwise select a shelter to keep them safe from the elements do not do so because of their perception of the shelter conditions.

The negative effects of a lack of privacy include continual exposure on the part of the homeless to people who perceive them as a constant nuisance. And there is no getting away from this exposure other than the briefest of reprieves when they can "find a spot" to be alone. Their behavior is always constrained as a result of their lacking a place for privacy. With no place to store food, they rely on acquiring food on a day-to-day basis. With no place to cook food, they rely on premade snacks and hot meals prepared by somebody else. With no access to a washing machine, they end up with dirty clothes that sometimes put people off by the accumulation of body odors. Unlike Pam and Conrad, few have access to a storage unit so they must carry everything they own around with them.

This leads us to the concept of the criminalization of mundane corporal acts. For instance, it is legal to drink behind closed doors, but not in public. It is legal to stand around idly in one's home, but in public it is loitering. To sleep in pub- 
lic with a tent or sleeping bag is condemned as illegal camping, while the same behavior in one's home or backyard is not considered a problem. To use one's own restroom is everyday and banal. To not have access to a restroom is, by necessity, to engage in public excretion, a crime. Sex in public is quick, uncomfortable, and illegal, while sex behind closed doors between consenting adults is not only condoned, but amounts to popular obsession. The homeless experience, by contrast, is constrained on all sides by the nature of the public situation they find themselves in.

The police "bugging people for small things," as Jerry put it, amounts to a form of aggressive surveillance. Along with their privacy, their freedom is also restricted. When Jerry talked of the police regularly dumping his beer, he was describing a situation only possible through extensive surveillance by the police. If they were not under surveillance, the police would not regularly detect open containers of beer. Further, panhandling is the only way to make continuous exposure to the public gaze into an asset. For many homeless people, panhandling is the only means available to make any money. With no means to work for a living, the homeless must rely on the generosity of the public.

The homeless sometimes end up with no recourse to be left alone unbothered. The police don't want people permanently out in the open; nor does anybody else, including the homeless themselves. The police suspect groups of homeless people-especially if they're in tents-of illegal behavior. And so they seize tents from the homeless and thereby snatch from them any real means of avoiding public visibility. This translates to an attempt at privacy that is rejected by the authorities; the means for their modicum of privacy is removed, taken away. Further, this seizing of tents from their owners is legal and justified by both public health interests and the complaints of pitched tents being an "eyesore." Some of the homeless hoped for housing stability in part to avoid police harassment, but the alternative options narrow to zero. The fact of embodiment, of having a physical body, becomes in this context an offense to the civic body, a crime of corporeality. The police have some degree of freedom in deciding the context of the existence of homeless people. They can look at somebody sitting, and criminalize it as loitering. They can look at somebody standing, and criminalize it as trespassing. Somebody lying down, well, that can be construed as illegal camping. And so the corporal acts of everyday life are at risk of being labeled "criminal."

Everything about homeless persons' lack of privacy is negotiated with the public in frames of restriction, reduction, and limitation. The lack of privacy they experience means they must devote considerable energy to coping with the public gaze, managing their performance of being in public, and occasionally attempting to make the most of it through panhandling. They have no solid recourse to privacy, and their lives suffer for it.

\section{Conclusion}

In the face of such a troubling trend whereby people are trapped in unwelcom- 
ing public space, how should society respond? The common approach has been to essentially ignore the issue, but as we've seen, this ends up being sorely inadequate at solving the problem itself. The evidence for reducing the gross number of homeless persons in a given city is supported by Housing First policies over the older strategy of first requiring a homeless person to acquire sobriety, a job, or some other semblance of stability prior to obtaining subsidized housing. In the places where Housing First has been implemented, the numbers of homeless have at times been brought to a "functional zero"-meaning effectively nobody is left behind. Naturally, this means there have been massive reductions in the number of chronically homeless persons on the street in areas where it has been used, and so the homeless issue can be solved, but so far only in this piecemeal fashion. By using broad strokes with Housing First, more cities can eliminate the homeless issues they happen to face (Padgett et al., 2015). But Housing First is not always met with enthusiasm by decision-makers in positions of power. It is sometimes disregarded as a method of catering to irresponsible and unseemly behavior and squandering limited tax revenues.

In addition to the Housing First strategy, which is effective at reducing the homeless population, we also need comprehensive preventive techniques put into action to keep people from becoming homeless in the first place. By creating low-income housing commensurate with local need, individuals and families run a greater chance of maintaining stable housing and avoiding homelessness (National Coalition for the Homeless, 2009). Governments are in a unique position to implement such strategies, since low-income housing is often provided at a rate lower than market cost, and thus needs to be subsidized by federal, state, or local authorities. Los Angeles County, which abuts Orange County, has one of the highest disparities in the nation between average earnings and average housing costs. When individuals and families are priced out of the housing market, it then comes as no surprise that many of them end up without a place to stay altogether.

\section{Acknowledgements}

Thanks to Peter Kao, California State Fullerton for editing assistance.

\section{References}

Duneier, M. (1999). Sidewalk. New York: Farrar, Straus and Giroux.

Gowan, T. (2010). Hobos, Hustlers, and Backsliders: Homeless in San Francisco. St Paul, MN: University of Minnesota Press. https://doi.org/10.5749/minnesota/9780816648696.001.0001

Gubrium, J. F., \& Holstein, J. (2002). Handbook of Interview Research, Context and Method. Thousand Oaks, CA: Sage Publication.

Gulcur, L., Stefancic, A., Shinn, M., Tsemberis, S., Fischer, S., Christian, J., \& Anderson, I. (2003). Housing, Hospitalization, and Cost Outcomes for Homeless Individuals with Psychiatric Disabilities Participating in Continuum of Care and Housing First Programes. Journal of Community \& Applied Social Psychology, 13, 171-186. 
https://doi.org/10.1002/casp.723

Jencks, C. (1995). The Homeless. Cambridge, MA: Harvard University Press.

Leff, H., Chow, C., Pepin, R., Conley, J., Allen, I., \& Seaman, C. (2009). Does One Size Fit All? What We Can And Can't Learn from a Meta-Analysis of Housing Models for Persons with Mental Illness. Psychiatric Services (Washington, D.C.), 60, 473-482. https://doi.org/10.1176/ps.2009.60.4.473

National Alliance to End Homelessness (2016). Chronically Homeless. Washington, DC: National Alliance to End Homelessness.

National Coalition for the Homeless (2009). Why Are People Homeless? Washington, DC: National Coalition for the Homeless.

National Health Care for the Homeless Council (2017). What Is the Official Definition of Homelessness? Nashville, TN: National Health Care for the Homeless Council.

Padgett, D., Henwood, B., \& Tsemberis, S. (2015). Housing First: Ending Homelessness, Transforming Systems, and Changing Lives. Oxford: University of Oxford Press. https://doi.org/10.1093/acprof:oso/9780199989805.001.0001 